\title{
Prevalence and antibiotic susceptibility of streptococcus spp. in cows with mastitis in Germi, Iran
}

\author{
Gharari Kia $^{1}{ }^{*}$, Ghasemi Mehdi ${ }^{2}$, Radjabalizade Keyvan ${ }^{2}$ \\ ${ }^{1}$ Department of Animal Science, Islamic Azad University, Germi, Iran \\ ${ }^{2}$ Department of Biology, Islamic Azad University, Ardabil, Iran
}

\section{Email address:}

kia.gharari@yahoo.com (G. Kia), mehdi_aidin@yahoo.com (G. Mehdi), keyradj@gmail.com (R. Keyvan)

\section{To cite this article:}

Gharari Kia, Ghasemi Mehdi, Radjabalizade Keyvan. Prevalence and Antibiotic Susceptibility of Streptococcus spp. in Cows with Mastitis in Germi, Iran. Animal and Veterinary Sciences. Vol. 2, No. 2, 2014, pp. 31-35. doi: 10.11648/j.avs.20140202.13

\begin{abstract}
Streptococci are frequently isolated from bovine mastitis in dairy cows with only limited information about the antimicrobial susceptibility of these organisms. The aim of this study was to investigate the prevalence of Streptococcus agalactiae isolated from clinical cases of bovine mastitis in Germi, Iran; and determine their susceptibility to some antibiotics. 700 milk samples collected from traditional and industrial dairy cattle husbandry suspected of having mastitic udders were submitted to laboratory for bacteriologic identification by biochemical and serological methods. The susceptibility patterns were studied by agar disk diffusion methods (ADDM). A total of 525 (75\%) of the milk samples streptococci isolate belonging to 3 species namely S. agalactiae (52.95\%), S. dysgalactiae (25.57\%) and S. uberis (18.48\%). All of isolates were resistant to streptomycin. Sensitivity to other antibiotics tested was varied. In comparison with other antibiotics amoxicillin and cephalexin were the most effective, in vitro. These species of streptococcus are of great public importance and the antibiotic susceptibility tests should be performed together with the identification of the bacterial agents in order to achieve effective treatment.
\end{abstract}

Keywords: Streptococcus Agalactiae, Antibiotic Susceptibility, Mastitis, Germi, Iran

\section{Introduction}

Inflammation of udder is called mastitis caused by various reasons. The most important and the most likely reason is that microorganisms enter into the breast tissue through the nipple due to some unfavorable conditions, such as age, beef, ulcers, poor hygiene; including the common disease that causes the huge substantial damage to livestock industry, milk production and health risks such as transfer of common zoonotic diseases $(1,2)$. Generally, mastitis due to damage in secreted cells in milk producing glands leads to an increase in minerals, especially sodium chloride, potassium loss, increase in immunoglobulin and non-protein nitrogen, in milk enzymes and $\mathrm{pH}$, decrease in absorption of calcium from the blood and reducing in the milk, reducing the amount of lactose, casein and fat and changes the properties osmotic milk and ultimately increases the cost of treatment. Broad categories of microorganisms such as bacteria, mycoplasma, yeasts and fungi are responsible for the disease, but the most important disease pathogen is Streptococcus group B, Streptococcus agalactiae (3, 4 and 5 ). The types of antibiotics can be pointed out to penicillin, streptomycin, neomycin, chloramphenicol, tetracycline, cephalexin, which they are used to treatment of livestock diseases whether injection or orally, may be entered into milk. Antibiotic residues in milk are important because it can cause health and industrial effects. These remaining can cause allergic reactions or increase in antibiotic treatment and may adversely affect the starter culture medium $(6,7$ and 8). However, other treatment methods also have been proposed, such as the antibacterial effect of herbs that are being studied (9). Mastitis is a disease that cattle farmers cannot take it easy and can combat with common and traditional therapies. Considering three factors environment, animal's disease susceptibility and microbes we can reduce the cost of fighting the disease considerably and timely or prevent damages by choosing of appropriate and effective antibiotics (9). Therefore, in this work we studied the origin of infection, transmission, treatment and prevention of mastitis considering the prevalence of mastitis and essential factors such as race, age and region of Germi; to return of affected cattle to maximum production. 


\section{Materials and Methods}

\subsection{Samples Collection}

Possible number of collected samples was calculated 700 cows in accordance with the following formula $(\alpha=0.05)$ from traditional and industrial dairy cattle husbandries including both native and non-native in Germi and subsidiary villages:

$$
\mathrm{n}=\frac{\mathrm{Z}_{a / 2^{2} \delta^{2}}}{\mathrm{~d}^{2}}
$$

$\mathrm{n}=$ number of samples

$\delta=$ variance

$\mathrm{Z} \alpha / 2=$ level of confidence

$\mathrm{d}=$ maximum difference between the mean of the sample mean

For sampling, suspected animal from different ages and races were selected after clinical examination using the California Mastitis Test (CMT), aseptically. First the tip of the pacifier was disinfected carefully with alcohol soaked cotton, and then few streams were discarded, next at least $100 \mathrm{cc}$ of milk were collected in sterile Falcon tubes with a 45-degree angle, and the door of tubes were closed immediately. Finally, collected milk samples were transported to the laboratory in compliance with the standard conditions up to 6 hours and maximum up to 12 hours at $4{ }^{\circ} \mathrm{C}$ in the Coleman (10).

\subsection{Isolation and Identification}

In the isolation process, first $1 \mathrm{cc}$ of each milk samples, separately, were poured into sterile BHI Broth and MacConkey Broth mediums to revitalize and enrich of studied bacteria, and then were incubated aerobically at $37{ }^{\circ} \mathrm{C}$ for 48 hours. Next, the cultures were purified on $7 \%$ sheep Blood Agar plates at the same conditions. Suspected colonies were tested by Gram staining method in terms of being cocci and gram-positive; in the next phase of identification, the catalase-negative and oxidase negative colonies were isolated and then Streptococcus agalactiae strain was differentiated due to Esculin hydrolysis, Carbohydrates utilization containing lactose, maltose, mannitol, raffinose, CAMP test and resistance to bacitracin from two other streptococci, Streptococcus dysgalactiae and Streptococcus uberis. Serological grouping of isolates were performed with a commercial Latex Agglutination Kit in order to identify of streptococcal groups A, B, C, D, F and G. Streptococci were tested using the broth method described by the manufacturer (Oxoid). Finally Isolates were purified and kept at refrigerator temperature for the next steps $(1,2,3$, 9, 11 and 12).

\subsection{Antibiotic Susceptibility of Strains}

For this purpose antimicrobial susceptibility of tested bacteria was performed by Kirby Bauer disk diffusion method according to Clinical and Laboratory Standards Institute (CLSI) guidelines in Mueller-Hinton Agar II (Oxoid) by using antibiotics penicillin, amoxicillin, cephalexin, gentamicin, tetracycline, vancomycin, neomycin and streptomycin; the overnight inoculum suspensions were adjusted to $0.5 \mathrm{McFarland}$ standard turbidity. Interpretation of the test results sensitive was based on CLSI criteria. Activity of eight antibiotics to each bacterial species was analyzed (1, 2, 7, 8, 18 and 19). Data was analyzed by using ANOVA to determine the influence of age, race and both of them on disease.

\section{Results}

The serological and biochemical characteristics of streptococci isolated are as shown in Table 1.

Table 1. Biochemical and serological identification of streptococci isolated from mastitic cows.

\begin{tabular}{|c|c|c|c|c|c|c|c|c|}
\hline \multirow[b]{2}{*}{ Organism } & \multicolumn{8}{|c|}{ biochemical and serological parameters } \\
\hline & haemolysis & $\begin{array}{c}\text { CAMP } \\
\text { test }\end{array}$ & $\begin{array}{c}\text { Esculin } \\
\text { hydrolysis }\end{array}$ & lactose & mannitol & Raffinose & $\begin{array}{c}\text { resistance to } \\
\text { bacitracin }\end{array}$ & Lancefield \\
\hline $\begin{array}{l}\text { Streptococcus } \\
\text { agalactiae }\end{array}$ & $\beta$ & + & - & + & - & - & + & B \\
\hline S. dysgalactiae & $\alpha$ & - & - & + & - & - & - & $\mathrm{C}$ \\
\hline S. uberis & $\alpha$ & - & + & + & + & - & - & Non-groupable \\
\hline
\end{tabular}

The isolates were found to belong to three distinct species namely Streptococcus agalactiae, S. dysgalactiae and $S$. uberis. The biochemical and serological characteristics of Streptococcus agalactiae studied was $\beta$ haemolysis, CAMP- positive, Esculin hydrolysisnegative, lactose-positive, mannitol- negative, Raffinose negative resistant to bacitracin and Lancefield B group. Out of the 700 milk samples studied for streptococcal infection, streptococcus species were isolated from $525(75 \%)$ of the milk samples (Table 2).

Table is set based on number positive and incidence (\%) of the region, race and age variables. Table 3 illustrates the antibiotic susceptibility test results for $S$. agalactiae, S. dysgalactiae and $S$. uberis isolates for eight antimicrobial agents. 
Table 2. Summary of Streptococci isolated from clinical mastitic Cows in Germi, Iran.

\begin{tabular}{|c|c|c|c|c|c|c|c|c|}
\hline \multirow{2}{*}{ region } & \multirow{2}{*}{ race } & \multirow{2}{*}{ age } & \multicolumn{2}{|c|}{ Streptococcus agalactiae } & \multicolumn{2}{|c|}{ S. dysgalactiae } & \multicolumn{2}{|l|}{ S. uberis } \\
\hline & & & No Positive & Incidence $(\%)$ & No Positive & Incidence $(\%)$ & No Positive & Incidence $(\%)$ \\
\hline \multirow{6}{*}{$\begin{array}{l}\text { Traditional (Rural) } \\
\text { dairy cattle } \\
\text { husbandry }(n=370)\end{array}$} & \multirow{3}{*}{ Native } & 4 & 29 & 7.84 & 13 & 3.51 & 8 & 2.16 \\
\hline & & 5 & 49 & 13.24 & 26 & 7.03 & 13 & 3.51 \\
\hline & & 6 & 66 & 17.84 & 38 & 10.27 & 29 & 7.84 \\
\hline & \multirow{3}{*}{ non-Native } & 4 & 12 & 3.24 & 3 & 0.81 & 2 & 0.54 \\
\hline & & 5 & 18 & 4.86 & 9 & 2.43 & 6 & 1.62 \\
\hline & & 6 & 24 & 6.49 & 15 & 4.05 & 10 & 2.70 \\
\hline \multirow{6}{*}{$\begin{array}{l}\text { Industrial (Urban) } \\
\text { dairy } \quad \text { cattle } \\
\text { husbandry }(n=155)\end{array}$} & \multirow{3}{*}{ Native } & 4 & 3 & 1.94 & 1 & 0.65 & - & - \\
\hline & & 5 & 9 & 5.81 & 4 & 2.58 & 3 & 1.94 \\
\hline & & 6 & 11 & 7.10 & 6 & 3.87 & 5 & 3.23 \\
\hline & \multirow{3}{*}{ non-Native } & 4 & 13 & 8.39 & 5 & 3.23 & 3 & 1.94 \\
\hline & & 5 & 19 & 12.26 & 12 & 7.74 & 6 & 3.87 \\
\hline & & 6 & 25 & 16.13 & 18 & 11.61 & 12 & 7.74 \\
\hline
\end{tabular}

Table 3. Susceptibility to different antibiotics of bacterial species isolated from udder secretions.

\begin{tabular}{llccccccc}
\hline \multirow{2}{*}{ Organism } & & \multicolumn{5}{c}{ Susceptible, \% } \\
& amoxicillin & penicillin & cephalexin & gentamicin & tetracycline & vancomycin & neomycin & streptomycin \\
\hline S. agalactiae & $92.62 \pm 1.1$ & $55.61 \pm 1.2$ & $78.90 \pm 1.3$ & $46.34 \pm 2.1$ & $23.27 \pm 2.4$ & $21.23 \pm 2.1$ & $7.63 \pm 1.2$ & 0 \\
S. dysgalactiae & $91.14 \pm 2.4$ & $53.22 \pm 2.1$ & $78.13 \pm 1.7$ & $45.66 \pm 1.9$ & $25.82 \pm 1.9$ & $24.18 \pm 1.5$ & $6.52 \pm 1.1$ & 0 \\
S. uberis & $88.50 \pm 2.6$ & $54.22 \pm 2.4$ & $79.02 \pm 2.6$ & $48.21 \pm 1.4$ & $27.41 \pm 1.7$ & $21.11 \pm 2.3$ & $8.91 \pm 0.9$ & 0 \\
\hline
\end{tabular}

\section{Discussion}

The examined strains of bacteria that gain entry into the teat canal and mammary gland are most frequently isolated as main etiological agents of clinical and subclinical mastitis in cows and it is the most significant economic drain on the worldwide dairy industry $(11,12,13,14,15$, 16 and 17). In this study, 278 of 525 isolates were identified as $S$. agalactiae. Overall, $52.95 \%$ of the strains tested were Streptococcus agalactiae, $25.57 \%$ were Streptococcus dysgalactiae, and $18.48 \%$ were Streptococcus uberis. According to the analysis, obtained by the GLM ANOVA, there are significant differences between the means of traditional and mechanized husbandries as well as among ages; in terms of the number and strain of bacteria. There are interaction effect between the "native and non-native" and "maintenance situations" (traditional and industrial).

The antimicrobial susceptibility were amoxicillin (92.62\%), cephalexin (78.90\%), penicillin (55.61\%), gentamicin $(46.34 \%)$, tetracycline $(23.27 \%)$, vancomycin $(21.23 \%)$ and neomycin $(7.63 \%)$ in S. agalactiae. Of 150 strains of $S$. dysgalactiae antibiotics susceptibility were amoxicillin (91.14\%), cephalexin $(78.13 \%)$, penicillin $(53.22 \%)$, gentamicin $(45.66 \%)$, tetracycline $(25.82 \%)$, vancomycin $(24.18 \%)$ and neomycin (6.52\%). The susceptibility of antibiotics against in S. uberis, from 97 analyzed, were amoxicillin (88.5\%), cephalexin (79.02\%), penicillin $(54.22 \%)$, gentamicin $(48.21 \%)$, tetracycline $(27.41 \%)$, vancomycin $(21.11 \%)$ and neomycin $(8.91 \%)$. The most interesting point is that all of strains were resistant to streptomycin. Amosun et al. reported that $S$. uberis accounted for $52.95 \%$ of 72 streptococcal isolates from 130 dairy cattle (3). All isolates identified as Streptococci in this study exhibited serological and biochemical characteristic similar to those described previously for bovine Streptococci by Amosun et al. (3). Definitely, the results of the present study indicate the accurate identification of streptococcal species. Work on the distribution of these organisms and define their role in bovine mastitis is in progress. There are similar or different data about antibiotic susceptibility reported by authors, who applied the disc diffusion method (18, 19, 20, 21 and 22) or MIC determination (23, 24, 25, 26, 27 and 28). It should be emphasized that many scientists assume that comparison of results achieved by different methods in the sensitivity testing is not legitimate $(29,30)$. However, from literature data it can be also concluded that both above mentioned methods gave comparable results $(31,32)$. From this study, it is visible that $S$. agalactiae strains were the most sensitive to amoxicillin and cephalexin. Other authors also reported a high sensitivity of this bacteria to the mentioned antibiotics (33, 34 and 35). Owens et al. found very high in vitro susceptibility of $S$. uberis, S. dysgalactiae, and other Streptococcus sp. To ampicillin, ceftiofur, cephapirin, cloxacillin, enrofloxacin, penicillin, pirlimycin, and tetracycline (36). The majority of authors have noted the increase in the resistance to antibiotics of bacteria, mostly staphylococci, isolated from mastitis (37, 38, 39 and 40). However, little evidence has been reported to suggest this increase is significant. Item Ebrahimi et al. identified that $S$. agalactiae showed high resistance rates to amoxicillin (76.92\%), penicillin (69.23\%), and ampicillin (61.53\%). Authors reported that MIC levels for S. agalactiae isolates were higher for herds that reported dry cow treating all cows, as opposed to herds that did not dry cow treat or only 
selectively treated cows. This study reiterated that some strains of $S$. agalactiae are resistant to beta-lactam antibacterial drugs. According to Ebrahimi et al. a high resistance rate was observed among $S$. uberis isolates, in particular, against penicillin (100\%), ampicillin (88.88\%) (41). According to Piepers et al., S. uberis was more frequently resistant to the penicillin within the class of penicillins (42). The distribution of pathogens isolated from mastitis samples differ considerably among countries and even among within a country. This could be potentially hazardous to humans and animals, e.g., in the case of milk consumption after inappropriate milk processing and the breached withdrawal period. It is necessary to monitor mastitis pathogens to assess any changes in their antibiotic resistance patterns.

This study was conducted to determine the presence of contagious mastitis agents the most active antibiotics against Streptococcus agalactiae and Streptococcus sp. strains with different incidences isolated from 525 bovine milk samples collected from 700 dairy cows in different traditional (rural) and industrial (urban) dairy cattle farms located in the Germi Region of Iran were amoxicillin, cephalexin, penicillin and all of strains were resistant to streptomycin dramatically.

\section{Acknowledgments}

The present study was supported by Research Fund of Islamic Azad University, Germi Branch, Iran.

\section{References}

[1] Serkan İ, Beren B, Enver Barış B, Omer E, Güven K. Presence and antibiotic susceptibility patterns of contagious mastitis agents (Staphylococcus aureus and Streptococcus agalactiae) isolated from milks of dairy cows with subclinical mastitis. Turk Vet. Anim. Sci. J 2013; 37: 569-574.

[2] Irena K, Modestas R, Vytautas Š, Raimundas M, Asta P, Česlova B. Prevalence of grampositive bacteria in cow mastitis and their susceptility to beta-lactam antibiotics. Vet. Med. Zoot. J 2011; 56 (78): 65-72.

[3] Amosun E. A, Ajuwape A.T.P, Adetosoye A. I. Bovine Streptococcal Mastitis in Southwest and Northern States of Nigeria. Afr. J. Biomed. Res 2010; 13: 33 - 37.

[4] El-Jakee J, Hableel H.S, Kandil M, Hassan O.F, Khairy E. A, Marouf S.A. Antibiotic Resistance Patterns of Streptococcus agalactiae Isolated from Mastitic Cows and Ewes in Egypt. Global Veterinaria J 2013; 10 (3): 264-270.

[5] Beenu J, Anuj T, Bharat B. B, Mayur K. J. Antibiotic resistance and virulence genes in Streptococcus agalactiae isolated from cases of bovine subclinical mastitis. VETERINARSKI ARHIV J 2012; 82 (5): 423-432.

[6] Lindmark-Mansson H, Branning C, Alden G, Paulsson. M. Relationship between somatic cell count, individual leukocyte populations and milk components in bovine udder quarter milk. International Dairy J 2006; 16: 717-727.
[7] Edward M, Henry L, Sebastian S, Anna K, Michal K. Antimicrobial susceptibility of bacteria isolated from cows with mastitis in 2006-2007. Bull. Vet. Inst. Pulawy. J 2008; 52: $565-572$.

[8] Anderson K. Up dote on Bovine mastitis .The Veterinary Clinics of North America J 1993; 9(3): 102-105.

[9] Bradly, A. J. Bovine mastitis: An evolving disease. The Veterinary J 2002; 164: 116-128.

[10] Iranian National Standards Organization,. Milk and dairy products - Sampling Guide. Third revision. Iran National standard of 326. 2008; pp 2-8.

[11] Ferguson J. D, Azzaro G, Gambina M, Licitra G. Prevalence of mastitis pathogens in Ragusa, Sicily, from 2000 to 2006. Dairy Sci. J 2007; 90: 5798-5913.

[12] Pitkälä A, Haveri M, Pyőrälä S, Myllys V, Hankonen-Buzalski T. Bovine mastitis in Finland 2001prevalence distribution of bacteria, and antimicrobial resistance. Dairy Sci. J 2004; 87: 2433-2441.

[13] Guérin-Faublée V, Carret G, Houpffschmitt P. In vitro activity of 10 antimicrobial agents against bacteria isolated from cows with clinical mastitis. Vet. Rec. J 2003; 152: 466-471.

[14] Malinowski E, Lassa H, Kłossowska A, Markiewicz H, Kaczmarowski M, Smulski S. Relationship between mastitis agents and somatic cell count in premilk samples. Bull Vet. Inst. Pulawy J 2006; 50: 349-352.

[15] Myllys V, Asplund K, Brofeldt E, Hirvelä-Koski V, Honkanen-Buzalski T, Juntilla J, Kulkas L, Myllykangas O, Niskanen M, Saloniemi H, Sandholm M, Saranpää T. Bovine mastitis in Finland in 1998 and 1995 - changes in prevalence and antimicrobial resistance. Acta. Vet. Scand J 1998; 39: 119-126.

[16] Bradley A.J, Leach K.A, Breen J.E, Green L.A, Green M.J. Survey of the incidence and etiology of mastitis on dairy farms in England and Wales. Vet Rec. J 2004; 160:253-257.

[17] Waage S, Skei H.R, Rise J, Rogolo T, Sviland S, Odegaard S.A. Outcome of clinical mastitis in dairy heifers assessed by reexamination of cases one month after treatment. J Dairy Sci. J 2000; 83: 70-76.

[18] Constable P.D, Morin D.E. Use of antimicrobial susceptibility testing of bacterial pathogens isolated from the milk of dairy cows with clinical mastitis to predict response to treatment with cephapirin and oxytetracycline. Am. Vet. Med. Assoc. J 2002; 221: 103-108.

[19] Erskine R.J, Walker R.D, Bolin C.A, Bartlett P.C, White D.S. Trends in antibacterial susceptibility of mastitis pathogens during a seven-year period. Dairy Sci. J 2002; 85: 1111-1118.

[20] Malinowski E, Pilaszek J, Kłossowska A, Sobolewska S, Sobolewski J. Changes of the antibiotic-sensitivity of bacteria isolated from clinically manifested mastitis in dairy-cows during the period of 1987-1996. Vet. Med. J 1997; 53: $722-725$.

[21] Malinowski E, Kłossowska A. Cow mastitis pathogen resistance to antibiotics. Vet. Med. J 2003; 59: 230-235.

[22] Malinowski E, Niewitecki W, Nadolny M, Lassa H, Smulski S. Effect of lysozyme dimer injections on results of intramammary treatment of acute mastitis in cows. Vet. Med. J 2006; 1395-1399. 
[23] Lehtolainen T, Shwimmer A, Shpigel N.Y, Honkanen-Buzalski T, Pyörälä S. In vitro antimicrobial susceptibility of Escherichia coli isolates from clinical bovine mastitis in Finland and Israel. Dairy Sci. J 2003; 86: 3927-3932.

[24] Oliveira A.P, Watts J.L, Salmon S.A, Aerestrup F.M. Antimicrobial susceptibility of Staphylococcus aureus isolated from bovine mastitis in Europe and in the United States. Dairy Sci. J 2000; 83: 855-862.

[25] Pitkälä A, Haveri M, Pyőrälä S, Myllys V, Hankonen-Buzalski T. Bovine mastitis in Finland 2001prevalence distribution of bacteria, and antimicrobial resistance. Dairy Sci. J 2004; 87: 2433-2441.

[26] Rajala-Schultz P.J, Smith K.L, Hogan J.S, Love B.C. Antimicrobial susceptibility of mastitis pathogens fromfirst lactation and older cows. Vet. Microbiol J 2004; 102: 33-42.

[27] Srinivasan V, Gillespie B.E, Lewis M.J, Nguven L.T, Headrick S.J, Schukken Y.H, Oliver S.P. Phenotypic and genotypic antimicrobial resistance patterns of Escherichia coli isolated from dairy cows with mastitis. Vet. Microbiol J 2007; 124: 319-328

[28] Yoshimura H, Kojima A, Ishimuru M. Antimicrobial susceptibility of Arcanobacterium pyogenes isolated from cattle and pigs. Vet. Med. B. J 2005; 47: 139-143.

[29] Klement E, Chaffer M, Leitner G, Shwimmer A, Friedman S, Saran A, Shpigel N. Assessment of accuracy of disc diffusion tests for the determination of antimicrobial susceptibility of common bovine mastitis pathogens: a novel approach. Microb Drug Resist. J 2005; 11: 342-350.

[30] Rajala-Schultz P.J, Smith K.L, Hogan J.S, Love B.C. Antimicrobial susceptibility of mastitis pathogens from first lactation and older cows. Vet. Microbiol J 2000; 102: 33-42.

[31] Gosden P.E, Andrews J.M, Bowker K.E, Helt H.A, MacGowan A.P, Reeves D.S, Sunderland J, Wise P. Comparison of modified Stokes' method of susceptibility testing with results obtained using MIC methods and British Society for Antimicrobial Chemotherapy breakpoints. Antimicrob Chemother J 1998; 42: 161-169.

[32] Potz N.A.C, Mushtaq S, Johnson A.P, Henwood C.J, Walker R.A, Varey E, Warner M, James D, Livermore D.M. Reliability of routine disc susceptibility testing by the British Society for Antimicrobial Chemotherapy (BSAC) method. Antimicrob Chemother J 2004; 53: 729-738.
[33] Guérin-Faublée V, Carret G, Houpffschmitt P. In vitroactivity of 10 antimicrobial agents against bacteria isolated from cows with clinical mastitis. Vet. Rec. J 2003; 152: 466-471.

[34] Malinowski E, Pilaszek J, Kłossowska A, Sobolewska S, Sobolewski J. Changes of the antibiotic-sensitivity of bacteria isolated from clinically manifested mastitis in dairy-cows during the period of 1987-1996. Vet. Med. J 1997; 53: $722-725$.

[35] Schröder A, Hoedemaker M, Klein G. Resistenzen von Mastitiserregern im norddeuschen Raum. Berl Münch Tierärztl Wochenschr J 2005; 118: 393-398.

[36] Owens W.E, Ray C.H, Watts J.L, Yancey R.J. Comparison of success of antibiotic therapy during lactation and results of antimicrobial susceptibility tests for bovine mastitis. Dairy Sci. J 1997; 80: 313-317.

[37] Turutoglu H, Ercelik S, Ozturk D. Antibiotic resistance of Staphylococcus aureus and coagulase-negative staphylococci isolated from bovine mastitis. Bull Vet. Inst. Pulawy J 2006; 50: 41-45.

[38] Reddy P, Qi C, Zembower T, Noskin G.A, Bolon M. Postpartum mastitis and community-acquired methicillinresistant Staphylococcus aureus. Emerg Infect Dis. J 2007; 13: 298-301.

[39] Pitkälä A, Haveri M, Pyőrälä S, Myllys V, Hankonen-Buzalski T. Bovine mastitis in Finland 2001prevalence distribution of bacteria, and antimicrobial resistance. Dairy Sci. J 2004; 87: 2433-2441.

[40] Myllys V, Asplund K, Brofeldt E, Hirvelä-Koski V, Honkanen-Buzalski T, Juntilla J, Kulkas L, Myllykangas O, Niskanen M, Saloniemi H, Sandholm M, Saranpää T. Bovine mastitis in Finland in 1998 and 1995 - changes in prevalence and antimicrobial resistance. Acta vet. Scand j 1998; 39: 119-126.

[41] Ebrahimi A, Nikookhah F, Nikpour S. Isolation of streptococci from milk samples of normal, acute and subclinical mastitis cows and determination of their antibiotic susceptibility patterns. Pakistan Journal of Biological Sciences 2008; 1: 148-150.

[42] Piepers S, De Meulemeester L, de Kruif A, Opsomer G, Barkema H.W, De Vliegher S. Prevalence and distribution of mastitis pathogens in subclinically infected dairy cows in Flanders, Belgium. Dairy Res. J 2007; 74: 478-483. 